\title{
MICROSTRUCTURE AND MICROHARDNESS EVALUATION FOR NiCrAIY MATERIALS MANUFACTURED BY SPARK PLASMA SINTERING AND PLASMA SPRAYING
}

\author{
Iosif Hulka*, RAdek MušÁlek, FrantišEK LukÁČ, Jakub KleČKa, \\ TOMÁŠ CHRÁSTKA \\ Czech Academy of Sciences, Institute of Plasma Physics, Za Slovankou 1782/3, 18200 Prague 8, Czech \\ Republic \\ * corresponding author: hulka@ipp.cas.cz
}

\begin{abstract}
NiCrAlY deposited by different thermal spraying methods is commonly used as the bond coat material in thermal barrier coatings (TBCs). In the present study, two experimental coatings were deposited by hybrid water stabilized plasma (WSP-H) and radio frequency inductively coupled plasma (RF-ICP) using the same feedstock powder. Spark plasma sintering (SPS) was used to manufacture a compact NiCrAlY from the same feedstock powder as a reference material. Microstructure, internal oxidation, phase characterization and quantification of the mechanical behaviour in terms of microhardness were studied. The investigations clearly showed microstructural and mechanical differences between the NiCrAlY samples manufactured by different plasma technologies. The results confirmed that SPS and RF-ICP provide dense structures with no oxides due to the fabrication under protective atmosphere and similar mechanical properties. Thus, RF-ICP may be used for deposition of very dense coatings with microstructure and hardness comparable to compacted materials prepared by SPS.
\end{abstract}

KEYWORDs: Microhardness, microstructure, NiCrAlY, plasma spraying, spark plasma sintering.

\section{INTRODUCTION}

The degradation of materials during service of turbine components in the field of energy production and aircraft industry is one of the major concerns in materials science research [1]. Applying thermal barrier coatings (TBCs) on the surface of the turbine components is a common method to protect the substrate material, which is usually manufactured from a Ni-based superalloy, against high temperature oxidation, thermal shocks and hot corrosion. The TBCs usually consist of i) bond-coat, which is used to reduce thermal stress at the coating-substrate interface while it improves the coatings adhesion to the substrate and provides oxidation protection, and ii) ceramic top-coat which ensures a low thermal conductivity acting like an insulating layer 2. The performance of TBCs is strongly influenced by the properties and chemical composition of the bond-coat. NiCrAlY-based alloy is one of the most common bond-coats used due to good oxidation resistance and good adhesion to the substrate 3 . There are several thermal spray methods to prepare NiCrAlY bond-coats. Among these methods, plasma spraying (PS) is one of the most common deposition technique. Hybrid water stabilized plasma spraying (WSP-H) is a new deposition method providing high plasma enthalpy allowing very high feed rates (tens of $\mathrm{kg} / \mathrm{h}$ ). The WSP-H plasma torch can operate at power up to $180 \mathrm{~kW}$ consuming about $15 \mathrm{slpm}$ of argon making it ideal for cost-effective spraying of large scale components [4. WSP-H spraying is typ- ically carried out in open-air atmosphere. Access of oxygen to hot metal may cause its intensive oxidation. Another plasma method which might be suitable for the deposition of novel NiCrAlY bond-coats, is radio frequency inductively coupled plasma (RF-ICP) which is a coating deposition method that operates in a controlled atmosphere eliminating internal oxidation of the coating during spraying. For both technologies, development of lamellar microstructure, resulting from consecutive impacts of molten droplets, is typical. Besides chemical composition, properties of the coating are dependent mainly on the quality of internal interfaces between these lamellae (so called splats), presence of voids (pores and cracks) and impurities (such as oxides). On the other hand, spark plasma sintering (SPS) enables fabrication of bulk materials in a controlled atmosphere. This process uses pulsing electrical discharge and pressure to compact powders. The process allows sintering of the powder particles providing materials with homogenous microstructure and free of pores. The drawback of the lab-scale SPS method is the manufacturing of rather small-sized samples typically measuring $20-50 \mathrm{~mm}$ in diameter and several millimetres high. Nevertheless, such coupons are more than enough for materials testing.

The oxidation of NiCrAlY is an important issue because the oxides formed within the bond-coat during deposition may for example hinder the formation of protective oxide film and thereby decrease the hightemperature oxidation resistance as reported by S.F. Chen at al. [5]. In the present study, the microstruc- 


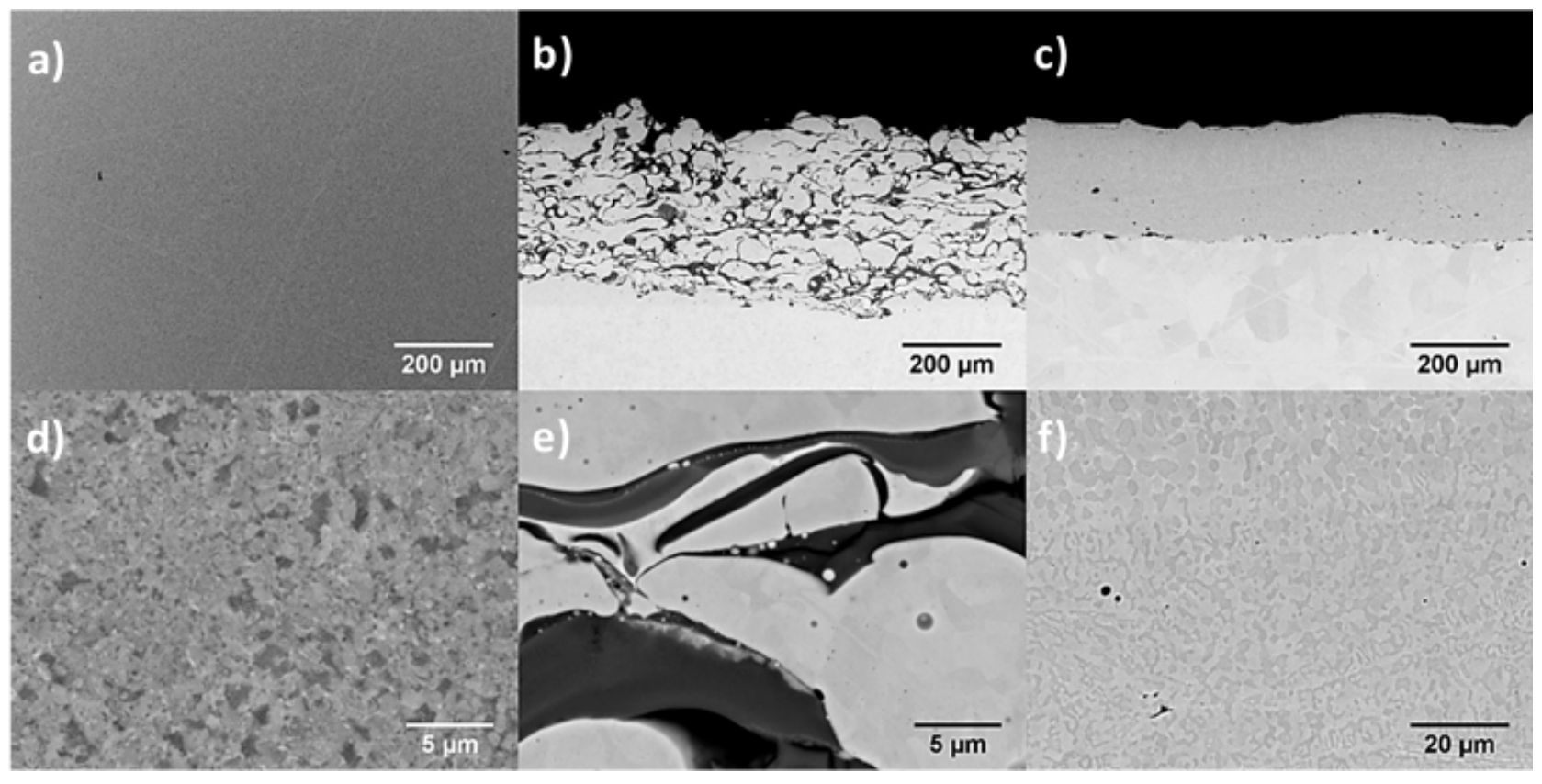

FigURE 1. Microstructure of samples in cross-section: low magnification of SPS sample (a), low magnification of WSP-H coating (b), low magnification of RF-ICP coating (c), high magnification of SPS sample (d), high magnification of WSP-H coating (e) and high magnification of RF-ICP coating (f).

ture, phases and the mechanical behaviour in terms of micro-hardness of SPS bulk material, WSP-H and RF-ICP coatings obtained from the same feedstock $\mathrm{NiCrAlY}$ powder were studied and compared in order to evaluate influence of microstructural features, in particular oxides and pores on their mechanical properties.

\section{EXPERIMENTAL}

\subsection{SAMPLES PREPARATION}

For the preparation of SPS sample and plasma sprayed coatings, a commercial NiCrAlY powder (Amperit 413.006, H.C. Starck GmbH, Germany) was used with a grain size in the range of 45-125 $\mu \mathrm{m}$. According to the manufacturer, the powder contains $21-23 \%$ Cr, $9-11 \%$ Al, 0.8-1.2\% Y and Ni in balance. Spark plasma sintering (SPS) process was carried out using a SPS system - type SPS 10-4 (Thermal Technology LLC, USA). The sintering was done at $1000{ }^{\circ} \mathrm{C}$ at $80 \mathrm{MPa}$ pressure for 4 minutes. The cooling rate was $100{ }^{\circ} \mathrm{C} / \mathrm{min}$. WSP-H 500 plasma torch (ProjectSoft HK, a.s., Czech Republic) operated at $400 \mathrm{~A}$ $(\sim 120 \mathrm{~kW})$ and with a feeding distance (FD) of $75 \mathrm{~mm}$ and $200 \mathrm{~mm}$ stand-off distance (SD) was used to deposit the WSP-H coating in the open-air atmosphere. The torch was mounted on a 6 -axis robot arm. The grit-blasted steel substrates $(20 \times 30 \times 2.5 \mathrm{~mm})$ were mounted on a rotating carousel. Cooling of the samples was carried out by air knives in order to prevent overheating of the substrate during deposition. The RF-ICP coating was prepared using Tekna 15 plasma system (Tekna, Canada). The torch was operated at $12 \mathrm{~kW}$ power using argon as protective atmosphere in the deposition chamber. The plasma was obtained from the mixture of $\mathrm{Ar}+\mathrm{H} 2$ and $\mathrm{Ar}$ was used also as a carrier gas for the powder injection into the torch. All the coatings were deposited on grit-blasted Hastelloy$\mathrm{X}$ substrate ( $\varnothing 25 \mathrm{~mm}$, thickness $4.9 \mathrm{~mm})$.

\subsection{SAMPLES CHARACTERIZATION}

Cross-sections of all samples were prepared following a standard metallographic procedure using a metallographic saw Secotom-50 (Struers, Denmark) with diamond blade, vacuum EpoFix epoxy impregnation (Struers, Denmark) and semi-automated polishing system Tegramin-25 (Struers, Denmark). Vickers hardness was measured by a Qness Q10A+ microhardness tester (Qness GmbH, Austria) on polished crosssections with $1 \mathrm{kgf}$ load. Microstructural investigation and observation of indents prepared during hardness measurements were carried out on a EVO MA 15 (Carl Zeiss SMT, Germany) scanning electron microscope (SEM) using Back Scattered Detector (BSD) in low vacuum mode. The local chemical composition of the samples was determined by energy dispersive X-ray microanalysis (EDS, XFlash 5010, Bruker) installed in the SEM. Phase composition was evaluated by X-ray diffraction (XRD) using D8 Discover diffractometer (Bruker, Germany).

\section{Results And Discussions}

The cross sections of the samples are presented in Figure 1 at low and high magnifications. In the SPS sample (Fig. 1a,d), neither pores or cracks are observed. The microstructure consists mainly of the $\beta$ $\mathrm{NiAl}$ intermetallic (dark grey) phase and the $\gamma-\mathrm{Ni}(\mathrm{Cr})$ 


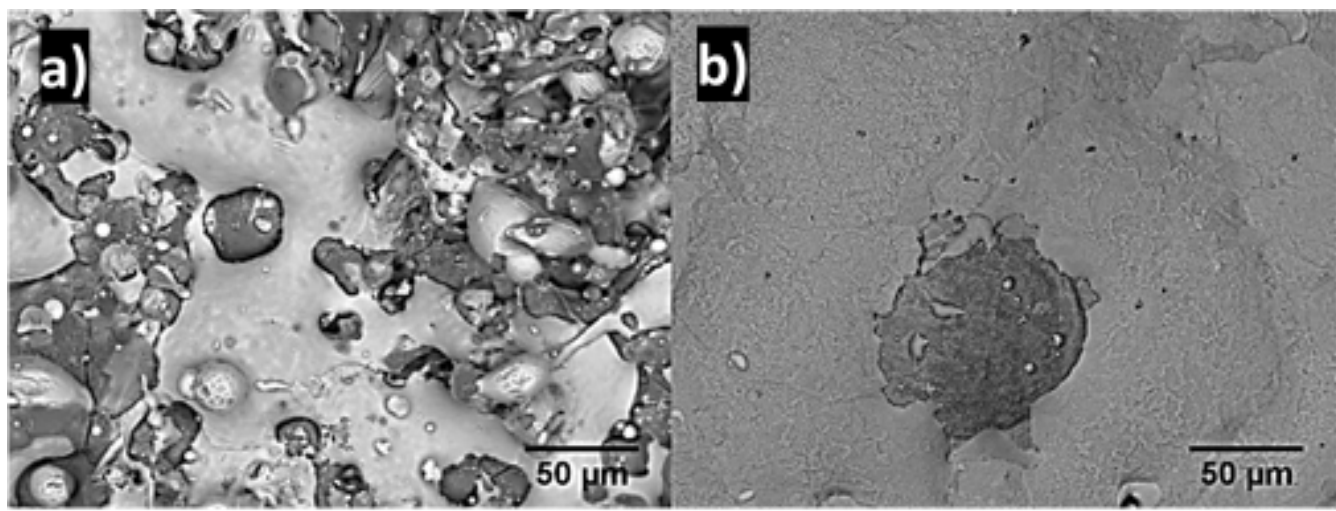

Figure 2. Top-surface morphology of as-sprayed WSP-H (a) and RF-ICP (b) coatings.

solid solution (light grey), as measured by EDS. WSP$\mathrm{H}$ coating shows structure typical for atmospheric plasma sprayed coatings consisting of splats, microcracks, un-bonded interfaces between splats and pores. The WSP-H coating (Fig. 1p,e) presents a rough surface due to the formation of asperities during spraying. These may be in beneficial in spraying of the whole TBC as they may improve adhesion of the top-coat. Internal oxidation took place during spraying which can be identified as dark areas within the coating. The dark areas are typical Al rich oxides and were found to be formed preferentially at the interfaces between metallic splats. Some cracking of these oxides was observed. The metallic matrix is enriched in $\mathrm{Ni}$, identified as light grey areas by EDS. The porosity results mainly from the splashing effect of the splats overlapping during spraying or due to gas inclusions between splats. With RF-ICP (Fig. 1 1 ,f) method, a dense coating with smooth surface, good bonding to the substrate, negligible degree of porosity and dendritic structure was obtained. The dendritic structure consists of $\beta$-NiAl phase dendrites (dark grey) rich in $\mathrm{Al}$ and $\gamma-\mathrm{Ni}(\mathrm{Cr})$ phase as interdendritic solid solution (light grey). The coating shows no oxidation, just residues of the grit-blasting alumina may be observed on the substrate-coating interface.

Figure 2 shows the surface morphology of the WSP$\mathrm{H}$ and RF-ICP sprayed coatings. The rough coatings deposited by WSP-H presents deformed and spread splats, re-solidified droplets and a visible interface between the metallic phase and oxides. During spraying, the molten powder particles hit the surface and flattened. Within the oxide splats, some cracking was observed. The RF-ICP coating has a smooth surface consisting of highly flattened metallic splats without any considerable oxidation or cracking.

Figure 3 shows the XRD diffractograms for the original feedstock powder and deposited coatings. The powder consists of two main phases: a $\gamma$-Ni (fcc) phase rich in $\mathrm{Cr}$ which contains the dispersed $\beta$-NiAl (bcc) phase which is typical for the NiCrAlY powder, as reported as well e.g. by M. M. Khorramirad et al. 6. The SPS and RF-ICP samples have similar patterns and consist of two major phases: $\gamma$-Ni phase rich in

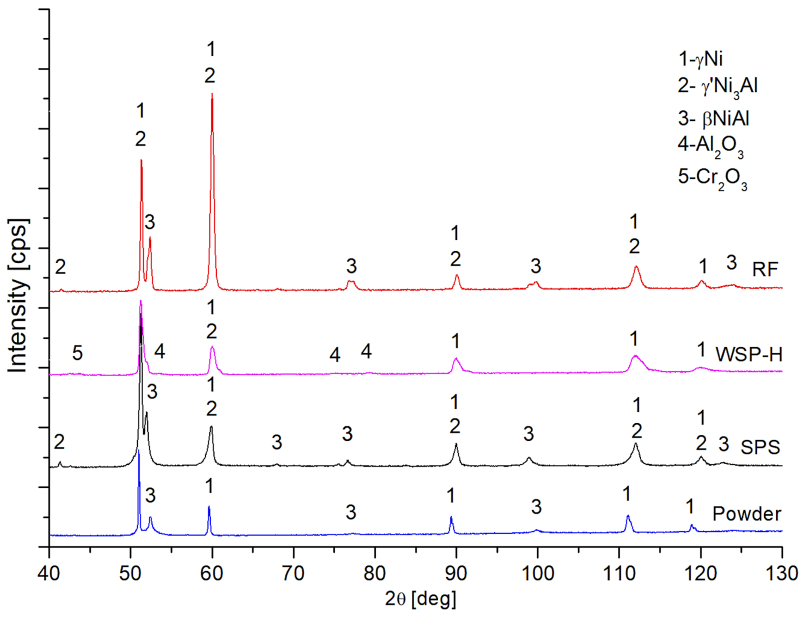

FiguRE 3. XRD patterns for NiCrAlY powder, SPS compact and coatings obtained by plasma technologies.

$\mathrm{Cr}$ and a $\beta$-NiAl inter-metallic phase, same as the feedstock powder. The $\gamma^{\prime}-\mathrm{Ni}_{3} \mathrm{Al}$ phase was identified in SPS and RF-ICP samples as well. The WSP-H coating did not show presence of this phase. $\mathrm{Al}_{2} \mathrm{O}_{3}$ and $\mathrm{Cr}_{2} \mathrm{O}_{3}$ - based oxides were identified instead.

For each prepared sample, cross-sectional microhardness measurements were measured by Vickers intender with $1 \mathrm{kgf}$ load. The mean value of microhardness was calculated as an average of 16 indentations made in the middle of the coating thickness and the results are presented in Figure 4 The results showed values of $546.8 \pm 8.5 \mathrm{HV} 1$ for the SPS bulk material, $280.0 \pm 37.1 \mathrm{HV} 1$ for the WSP-H coating and $556.6 \pm 27.9 \mathrm{HV} 1$ for the RF-ICP coating. The difference between the SPS and RF-ICP coatings is subtle, however it can be noticed that the SPS sample presents lower fluctuations in the measurements which might be attributed to a more homogenous composition of the material. The WSP-H coating has almost $50 \%$ lower hardness value, compared to the previous mentioned samples and also the highest fluctuation among the results. This fact is associated with a higher degree of porosity, presence of cracks and brittle oxides. 

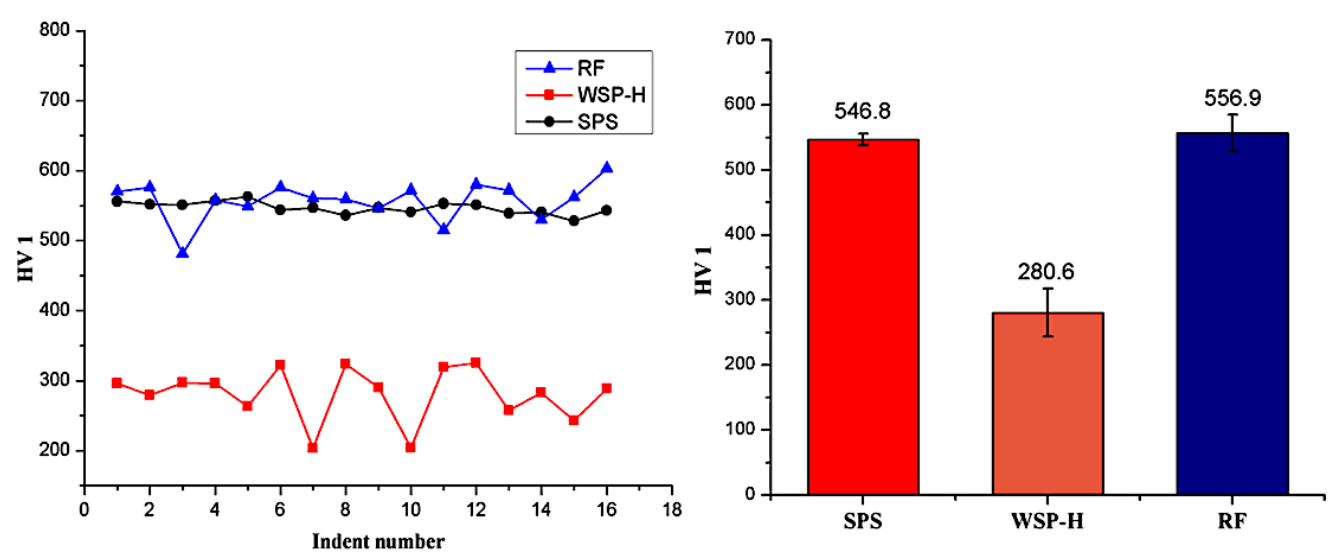

FiguRE 4. Measured values of cross-sectional hardness in half thickness of coatings/SPS sample.

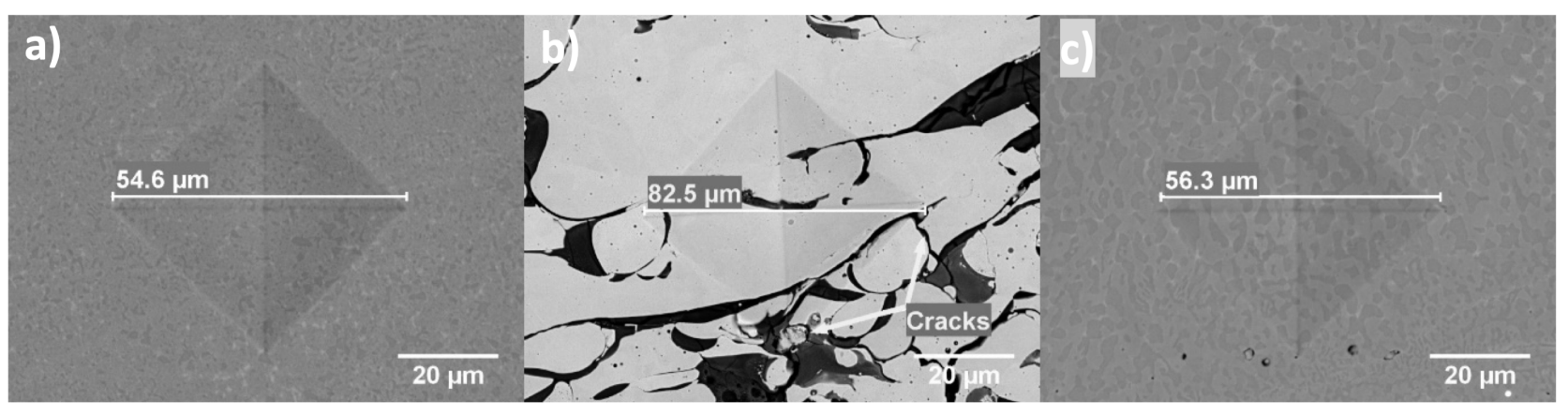

FiguRE 5. SEM micrographs of typical indents for SPS sample (a), WSP-H coating (b) and RF-ICP coating (c).

Figure 5 shows SEM images of typical indents of analysed samples. The uniformity of microstructure and lack of cracks network formation in the vicinity of the indents were noticed in the SPS and RF-ICP samples indicating that both materials have a good ductility. The microstructure was fine enough to include a representative number of microstructural features present in these two materials, which may explain a low scatter in the hardness values. The WSP-H coating developed cracks in the oxide rich areas (dark areas) due to their inherently brittle behaviour. $\mathrm{Mu}-$ tual sliding of the splats was also observed.

\section{Conclusions}

The aim of the paper was to compare at microscopic level mechanical behaviour of NiCrAlY coatings and bulk material prepared by different plasma methods from the same commercially available feedstock powder. The morphology, phases and mechanical performances were studied and the main conclusion were as follows:

- Using different plasma techniques, NiCrAlY bulk material and coatings with potentially interesting microstructures can be obtained;

- Due to high achievable feed rate, WSP-H technology can be used for efficient deposition of coatings on large areas. Formation of splats with distinguish- able splat boundaries was observed. Spraying in the open air led to considerable internal oxidation of the coatings and formation of brittle oxides. As a result, lower ductility and reduction of hardness value by $50 \%$ compared to the other samples was observed. On the other hand, the surface presents a rough surface which is favourable for deposition of top coat;

- The results confirmed that SPS and RF-ICP samples present dense structures consisting mainly by $\beta$-NiAl intermetallic phase and the $\gamma-\mathrm{Ni}(\mathrm{Cr})$ solid solution with no oxides due to the protective atmosphere in both processes. Nevertheless, size of the components which may be processed by SPS and RF-ICP techniques is limited by the size of the sintering tool and the deposition chamber, respectively;

- From mechanical behaviour point of view, the SPS and RF-ICP samples showed similar behaviour, thus RF-ICP may be used for deposition of very dense coatings with microstructure and hardness comparable to those prepared by SPS.

\section{ACKNOWLEDGEMENTS}

The authors gratefully acknowledge Czech Science Foundation for financial support of the present research under project no GA19-14339S entitled "High temperature preparation of advanced refractory materials by inductively 
coupled plasma in controlled atmosphere".

\section{REFERENCES}

[1] M. Mayoral, J. Andrés, M. Bona, et al. Aluminium depletion in nicraly bond coatings by hot corrosion as a function of projection system. Surface and Coatings Technology 202(9):1816 - 1824, 2008. DOI:10.1016/j.surfcoat.2007.07.068.

[2] R. Musalek, O. Kovarik, J. Medricky, et al. Fatigue testing of tbc on structural steel by cyclic bending. Journal of Thermal Spray Technology 24(1):168-174, 2015. DOI:10.1007/s11666-014-0180-4

[3] J. Song, K. Ma, Y. Li, et al. High temperature microstructure and microhardness evolution in dense nicraly bulk material fabricated by spark plasma sintering. Materials Science and Engineering: A 528(7):3210 - 3217, 2011. DOI:10.1016/j.msea.2010.12.094

[4] J. Medricky, R. Musalek, M. Janata, et al. Cost-effective plasma spraying for large-scale applications. In ITSC 2018 - Proceeding of International Thermal Spray Conference. 2018.

[5] S. Chen, S. Liu, Y. Wang, et al. Microstructure and properties of hvof-sprayed nicraly coatings modified by rare earth. Journal of Thermal Spray Technology 23:809-817, 2014. DOI:10.1007/s11666-014-0097-y

[6] M. Khorramirad, M. Rahimipour, S. Hadavi, K. Shirvani. Preoxidation of bond coat in in-738lc/nicraly/lamgal ${ }_{11}$ o19 thermal barrier coating system. Ceramics International 44(18):22080 - 22091, 2018. DOI:10.1016/j.ceramint.2018.08.318. 